\title{
Correction of Tilted Cartilaginous Nasal Dorsum with Clocking Suture Single Technique
}

\author{
Gyu-Sung Choi, Young-Bum Ko, and Yong Gi Jung \\ Department of Otorhinolaryngology-Head and Neck Surgery, Samsung Changwon Hospital, Sungkyunkwan University \\ School of Medicine, Changwon, Korea
}

클락킹 봉합 단일 기법을 이용한 연골성 사비의 교정

최규성 · 고영범 · 정용기

성균관대학교 의과대학 삼성창원병원 이비인후과학교실

\author{
Received April 9, 2017 \\ Revised May 2, 2017 \\ Accepted May 2, 2017 \\ Address for correspondence \\ Yong Gi Jung, MD, PhD \\ Department of Otorhinolaryngology- \\ Head and Neck Surgery, \\ Samsung Changwon Hospital, \\ Sungkyunkwan University \\ School of Medicine, \\ 158 Paryong-ro, Masanhoewon-gu, \\ Changwon 51353, Korea \\ Tel $+82-55-233-5982$ \\ Fax $+82-55-233-5441$ \\ E-mail ent.jyg@gmail.com
}

Background and Objectives Deviated nose is a commonly encountered deformity, and the correction of deviated nose is the most difficult part of septorhinoplasty. Generally, additional cartilaginous graft is required for straightening the deviated segment. However, there are many cases where sufficient cartilage grafts are not available due to revision surgery or cases with small cartilage. In such cases, tilted cartilaginous dorsum should be corrected without grafting. The purpose of this study is to evaluate the usefulness of clocking suture single technique for cartilaginous deviation by analyzing the surgical results of cases who underwent corrective rhinoplasty without any cartilaginous graft.

Subjects and Method From June 2009 to June 2016, 43 patients with tilted cartilaginous dorsum were corrected with clocking suture single technique. Cases underwent additional graft for straightening dorsum were excluded. The patients' medical records and facial photographs were analyzed to assess surgical outcomes and complications. Surgical outcomes were graded as excellent, fair and poor according to patients' satisfaction and evaluation by two physicians Results Mean follow up period was 15.4 (5-39) months. There were 39 patients $(90.7 \%)$ with excellent result, 3 patients (7.0\%) with fair results, and 1 patient $(2.3 \%)$ with poor result. Augmentation was performed with expanded polytetrafluoroethylene or septal cartilage in 26 patients $(60.5 \%)$ and dorsal hump was removed in 22 patients $(51.2 \%)$. Concomitant augmentation didn't affect surgical results. No postoperative complication such as infection or inflammation were found.

Conclusion The clocking suture single technique is an effective surgical method for the correction of dorsal cartilaginous deviation.

Korean J Otorhinolaryngol-Head Neck Surg 2017;60(7):342-6

Key Words Cartilage $\cdot$ Clocking suture $\cdot$ Deviated nose $\cdot$ Nose deformity $\cdot$ Rhinoplasty.

\author{
서 론 \\ 사비(deviated nose)는 콧등이 얼굴의 중앙선에서 벗어나 한 \\ 쪽으로 편위된 상태를 말한다. 외상에 의해 발생하는 경우가 \\ This is an Open Access article distributed under the terms of the Creative Commons \\ Attribution Non-Commercial License (http://creativecommons.org/licenses/by-nc/4.0) \\ which permits unrestricted non-commercial use, distribution, and reproduction in any \\ medium, provided the original work is properly cited.
}

많으나 성장과 더불어 자연적으로 발생하기도 하며 사비가 발 생한 위치에 따라 골성(bony) 사비, 연골성(cartilaginous) 사비, 복합성 사비로 나눌 수 있다. 코는 얼굴의 중앙에 위치하여 사람의 외모를 결정하는 데 중요한 역할을 하며, 사비가 있는 경우 얼굴의 모습에 큰 영향을 미칠 뿐 아니라 대부분의 경우 비중격 만곡을 동반하여 원활한 비강 호흡을 방해한다. 최 근 경제 및 의료 수준이 과거에 비해 향상되면서 진학이나 취 
업, 외모 관리를 위하여 성형에 대한 수요가 늘어나고 있으며, 사비의 교정은 환자들이 코성형을 위해 병원에 내원하는 흔한 이유 중 하나이다.

골성 사비의 교정을 위해 대부분의 경우 절골술(osteotomy) 이 필요하며,1) 여러 방법의 절골술이 소개되어 있지만 각 방 법 간의 기본적인 개념에는 큰 차이가 없다. 그러나 연골성 사 비 교정의 경우 연골의 크기 및 성질, 사용 가능한 연골의 양, 휘어 있는 연골의 정도에 따라 다양한 교정 방법이 적용될 수 있으며, 펼침 이식(spreader graft)과 같은 추가적인 연골 이 식을 이용하여 교정하는 경우가 많다.,3)

연골성 사비의 정확한 교정을 위해서는 비중격 연골과 상외 측 비연골(upperlateral cartilage) 사이의 연결을 완전하게 분 리하여 변형을 유발한 외인성 요인들을 제거하고, 필요한 경 우 추가적인 이식물이나 상외측 비연골을 이용한 자가 펼침 이 식(autospreader flap) 등을 부목으로 사용하여 휘어진 부분 을 교정한다. ${ }^{4)}$ 이식에 가장 우선적으로 사용되는 재료는 자가 연골이며 곧고 일정강도를 가지는 이식물이 필요하기 때문에 비중격 연골이 선호된다. ${ }^{5)}$ 그러나 이전에 수술을 받았거나 외 상 등으로 비중격 연골에 손상 및 소실이 있는 경우 이식에 필 요한 충분한 크기의 연골을 얻을 수 없으며, 비중격의 심한 변 형이 있는 경우 연골 또한 변형되어 비배부 이식물로 사용하 기에 적합하지 않은 경우가 있다. ${ }^{6}$ 또한 동양인의 경우 코를 구성하는 연골의 크기가 작고 두께가 얇은 경우가 많아서 충 분한 연골 이식물을 얻기 어려운 경우가 많다. ${ }^{7-9)}$ 이러한 경우 다른 부위의 연골 채취를 위해 추가적인 술기가 요구되고 수 술에 필요한 시간도 늘어나 합병증을 증가시키는 요인이 될 수 있다.

클락킹 봉합(clocking suture)은 상외측 비연골과 비중격 연 골 상연을 비대칭 수평 봉합하는 방법으로 1993년 처음 소개 되었으며, 펼침 이식 등의 방법에 비해 널리 사용되지 않았으 나, 2004년 Pontius와 Leach ${ }^{10}$ 가 사비 교정을 위한 새로운 수 술 기법으로 다시 소개하며 알려지게 되었다. ${ }^{11)}$ 이 수술 기법 은 상외측 비연골과 비중격 연골 자체의 탄성을 이용하여 연 골성 사비를 교정하는 방법으로 연골의 탄성이 충분한 서양인 의 경우 유용한 방법으로 보고되고 있으나 상대적으로 연골 이 약한 동양인에서의 유용성은 보고된 바가 없다.

저자들은 비배부 교정을 위한 추가적인 이식물을 사용하 지 않고 클락킹 봉합 단일 기법을 이용하여 연골성 사비를 교 정한 환자들의 수술 결과를 분석하여 연골이 상대적으로 약 한 동양인의 사비 교정술에서 유용하게 사용될 수 있는지 알 아보고자 하였다.

\section{대상 및 방법}

2009년 6월부터 2016년 6월까지 일인의 술자에 의해 기능적 코성형술을 시행받은 환자들의 의무기록을 조사하여, 연골 성 사비 교정을 위해 클락킹 봉합 단일 기법으로 사비 교정술 을 시행받고 5 개월 이상 추적 관찰하였던 43 명을 대상으로 연구를 시행하였다. 골성 사비, 또는 골부와 연골부의 복합성 사비로 판단되어 절골술을 시행한 환자군과 연골성 사비 교 정을 위해 펼침 이식 등의 추가 이식물을 삽입한 환자는 본 연 구에서 제외하였다. 사비 교정과 함께 시행된 융비술 및 작은 비혹(nasal hump) 제거를 위해 절골술을 사용하지 않고 갈 아서(rasping) 비혹 제거를 시행한 환자는 본 연구에 포함되 었다. 환자의 의무기록을 조사하여 나이, 성별, 융비술 여부와 높이, 비혹 제거동반여부, 코 수술 과거력, 술 후 합병증, 수술 결과에 대한 주관적인 만족도, 술자의 만족도에 대해 조사하 였다.

43예의 증례 모두 전신마취하에 단일 술자(YJ Jung)에 의해 수술이 시행되었다. 경비주(transcolumellar) 절개술을 통한 비외 접근법으로 수술을 시행하였고, 비중격에 추가적인 점막 절개를 시행하지 않고 양측 하외측 비연골(lower lateral cartilage)의 내측각(medial crus)을 분리하여 비중격에 접근하였 다. 양측 비중격 점막연골막(mucoperichondrial) 피판을 모 두 거상하였고, 연골막하 박리(subperichondrial dissection) 를 상부로 연장하여 비중격 연골과 상외측 비연골을 완전하 게 분리하였다. 골성 비혹이 있는 경우 갈아서 제거하였으며 연골성 비혹은 10 번 또는 15 번 날을 이용하여 제거하였다. 연 골성 만곡의 볼록한(convex) 면의 상외측 비연골 내측 자유 연(free margin)에서 비중격 연골의 상연을 향하여 두측에서 미측으로(cephalocaudal) 5-0 Polydioxanone(PDS; Ethicon, Somerville, NJ, USA)을 이용하여 봉합하였고 연골의 강도 에 따라 단순 봉합 또는 수평 매트리스 봉합법을 시행하였다. 이후 비중격 연골의 상연에서 오목한(concave) 면의 상외측 비 연골 자유연 방향으로 두측에서 미측으로 같은 방법으로 봉 합을 하였다. 2004년 소개된 본 기법에 대한 기술에는 비중격 연골의 만곡을 유발하는 연골의 내부 탄성을 감소시키기 위 해 비중격 연골의 상연에 절개를 시행하는 것으로 기술되어 있으나, ${ }^{10)}$ 본 연구에 포함된 환자에서는 추가 절개는 시행하지 않았다. 만곡부위가 중앙으로 오도록 봉합 시에 적정한 힘이 가해지도록 하여 고정하는 것이 중요하며 봉합은 연골의 크 기 및 탄성에 따라 일측에 2 3회 시행하였다(Fig. 1). 융비술 이 필요한 경우 자가 비중격 연골 또는 Surgiform(Surgiform Technology, Lugoff, SC, USA)을 사용하였으며 절개 부위 봉 합 후 양측 비강에 실리콘 시트(medical grade silicone sheet- 
ing; Bioplexus, Ventura, CA, USA)를 삽입하고 콧등의 모 양이 비틀어지지 않도록 외비 부목(Denver Splint; Sum-mit Medical, St. Paul, MN, USA)을 거치하였다. 술 후 일주일 동안 경구 항생제를 투여하였고 비강 실리콘 시트 및 외비 부목을 술 후 일주일에 제거하였다.

수술 결과에 대한 환자의 주관적인 만족도는 만족과 불만

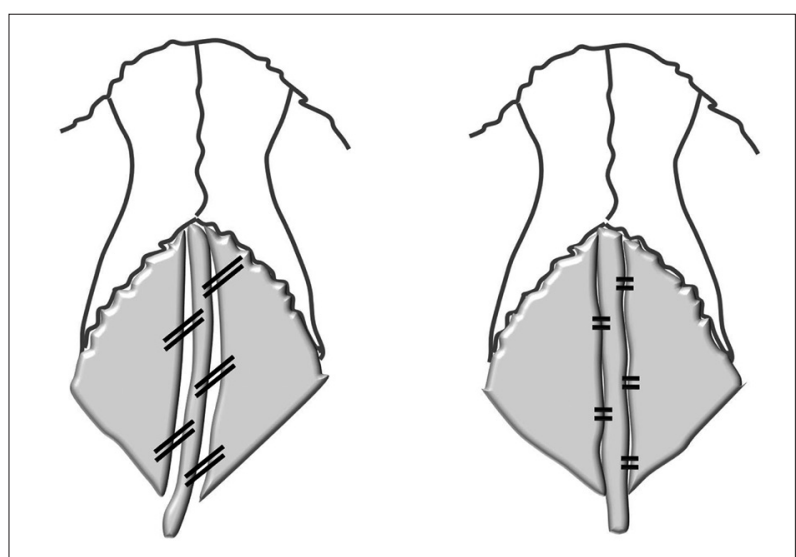

Fig. 1. Clocking suture technique. Bilateral upper lateral cartilages were completely separated from cartilaginous dorsal septum through submucosal pocket. Two or three sutures were made cephalocaudally on the convex side of deviation between dorsal septum and upper lateral cartilage. Then two or three sutures made cephalocaudally on the concave for securing the midline position of cartilaginous dorsum.

Table 1. Characteristics of enrolled patients

\begin{tabular}{ll}
\hline Mean age & $\begin{array}{c}25.9 \text { years old } \\
(16-51)\end{array}$ \\
Gender (male/female) & $34 / 9$ \\
Men follow up period & $15.4(5-39)$ months \\
Concomitant augmentation & $26(60.5 \%)$ \\
Concomitant hump removal & $22(51.2 \%)$ \\
Revision cases & $4(9.3 \%)$ \\
Aesthetic results (excellent/fair/poor) & $39(90.7 \%) / 3(7.0 \%) /$ \\
& $1(2.4 \%)$ \\
Postoperative infection or inflammation & 0 \\
\hline
\end{tabular}
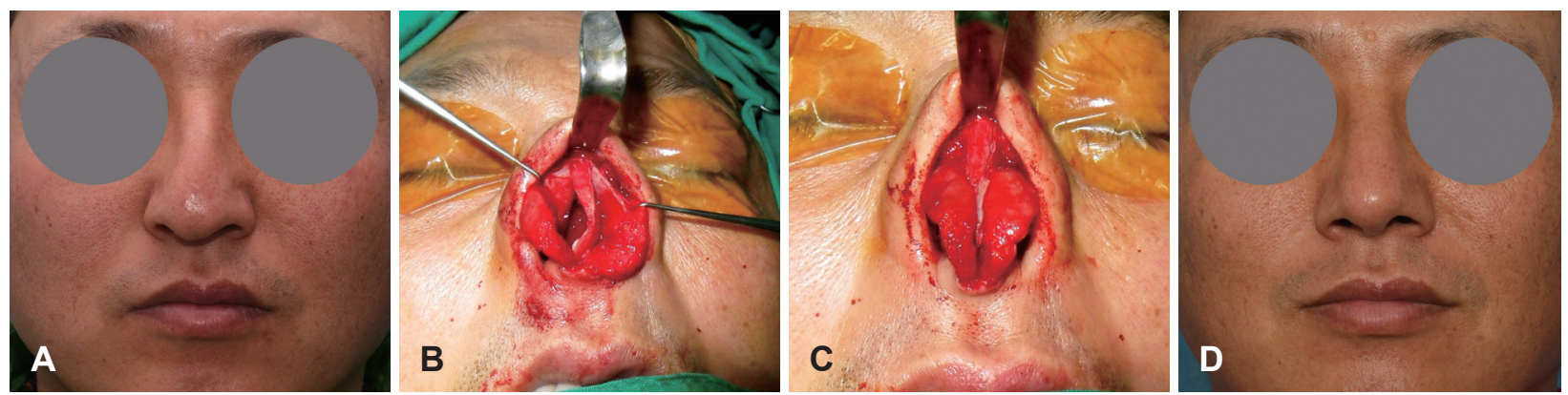

Fig. 2. Facial photos of "excellent" case. Preoperative photo. Cartilaginous dorsum and nasal tip are severely deflected to right side (A). After division of upper lateral cartilage from dorsal septum, deflected cartilaginous dorsum is identified (B). After multiple clocking sutures, deviated segment was corrected (C). 11-month postoperative photo. Deviated nose is corrected. Augmentation wasn't performed (D). 

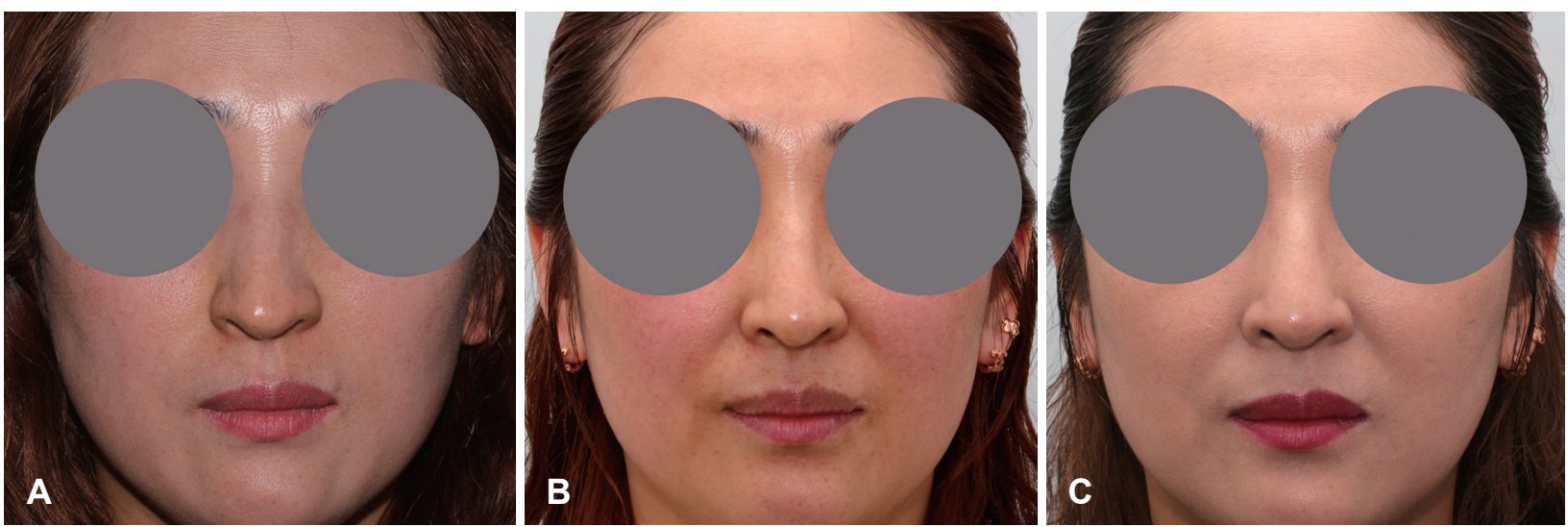

Fig. 3. Facial photos of "poor case." Dorsal hump and cartilaginous deviation are identified (A). 3-month postoperative photo. There is depression at left cartilaginous dorsal side wall (B). 5-month postoperative photo after revision surgery. Attachment between left upper lateral cartilage and dorsal septum was repaired (C).

Table 2. Cases of incomplete correction after clocking suture single technique in deviated nose

\begin{tabular}{lccccc}
\hline \multicolumn{1}{c}{ Aesthetic result } & Detection of problem (postoperative) & Age/sex & Augmentation & Hump removal & Revision case \\
\hline Poor case & 3 months & $42 / F$ & Yes & Yes & No \\
Fair case 1 & 1 month & $25 / M$ & No & Yes & No \\
Fair case 2 & 1 month & $29 / M$ & No & No & Yes \\
Fair case 3 & 2 months & $38 / M$ & Yes & No & No \\
\hline
\end{tabular}

Table 3. Impact of augmentation on surgical outcome

\begin{tabular}{lrrrr}
\hline \multirow{2}{*}{$\begin{array}{c}\text { Surgical } \\
\text { outcome }\end{array}$} & \multicolumn{2}{c}{ Augmentation } & & p-value \\
\cline { 2 - 3 } Excellent & No & & \\
Fair or poor & 24 & 15 & 39 & \\
\hline Total & 2 & 2 & 4 & \\
\hline
\end{tabular}

Table 4. Impact of hump removal on surgical outcome

\begin{tabular}{lrrrrr}
\hline \multirow{2}{*}{$\begin{array}{c}\text { Surgical } \\
\text { outcome }\end{array}$} & \multicolumn{2}{c}{ Hump removal } & & p-value \\
\cline { 2 - 3 } & Yes & No & & \\
\hline Excellent & 20 & 19 & 39 & \\
Fair or poor & 2 & 2 & 4 & \\
\hline Total & 22 & 21 & 43 & 0.679 \\
\hline
\end{tabular}

Table 5. Impact of revision surgery on surgical outcome

\begin{tabular}{lcrrrr}
\hline \multirow{2}{*}{$\begin{array}{c}\text { Surgical } \\
\text { outcome }\end{array}$} & \multicolumn{2}{c}{ Revision surgery } & & p-value \\
\cline { 2 - 3 } Yes & No & & \\
\hline Excellent & 3 & 36 & 39 & \\
Fair or poor & 1 & 3 & 4 & \\
\hline Total & 4 & 39 & 43 & 0.334 \\
\hline
\end{tabular}

스럽게 교정되었다(Fig 3). Fair로 분류된 3명의 환자들은 각 각 수술 후 1 개월과 2개월에 수술부위 부종이 감소되며 사비 가 일부 덜 교정된 부분이 관찰되었으며, 3예 모두 환자들은 이 부분에 대해 불만을 제기하지 않았고 평가자 중 1 명이 사 비가 일부 덜 교정되었음을 확인하였다. 3 예 모두 환자들이 재수술을 원하지 않아 추가적인 치료 없이 경과 관찰하였다
(Fig. 3). Fair와 poor로 분류된 환자들은 Table 2에 정리하였 다. 함께 시행한 융비술 $(p=0.521)$, 비혹 제거술 $(p=0.679)$ 및 재 수술 여부 $(p=0.334)$ 는 수술 결과에 영향을 미치지 않았다(Table 3,4 , and 5). 연구에 포함된 모든 환자에서 급성기 또는 후 기에 수술부위 염증 및 감염, 출혈 등 수술과 관련된 합병증 은 관찰되지 않았다.

\section{고 찰}

본 연구에 포함된 43 명의 환자 중 1 명을 제외한 42 명이 수 술 결과에 만족하였으며, 이러한 결과로 판단할 때 클락킹 봉 합 단일 기법은 연골이 상대적으로 약한 동양인의 연골성 사 비 교정에 있어서 훌륭한 대안이 될 수 있으리라 생각한다. 그 러나 모든 환자에서 클락킹 봉합 단일 기법을 선택할 수는 없 다. 저자들 또한 연골성 사비 교정을 시행할 때 펼침 이식을 많 이 사용하며 연골의 만곡이 매우 심한 경우 Song 등리 에 의해 보고된 절단 후 재봉합( $\mathrm{L}-$ strut cutting and suture)도 사용한 다. 저자들이 수술 중 클락킹 봉합 단일 기법을 적용한 기준 은 다음과 같다. 1) 양측 상외측 비연골의 모양 및 크기가 비 교적 대칭적이고, 2) 비중격 연골의 상연에 급격한 변형이 없 어야 하며, 3) 환자의 내측 비밸브에 기능적 문제가 없고, 4) 비중격 상연의 연골이 비대칭 견인 봉합을 견딜 정도의 탄성 을 가지고 있는 경우 본 술식을 적용하였다. 양측 상외측 비 연골의 모양 및 크기가 비대칭이거나 비 밸브 기능에 문제가 
있는 경우, 비중격 연골이 매우 약한 경우 펼침 이식을 시행하 였고, 비중격 상연의 급격한 변형이 있는 경우 절단 후 재봉합 기법을 적용하였다.

비배부 만곡의 치료에 대해서는 기존에도 많은 연구 결과 및 단계적 접근 방법들이 발표되어 수술을 시행하는 임상의들에 게 많은 도움이 되고 있다. ${ }^{1,3,6,13)}$ 그러나 이러한 논문에서 클라 킹 봉합이 연골성 비배부 만곡의 치료법으로 소개되는 경우 는 많지 않으며 이는 아직 해당 수술 기법에 대한 연구 논문 및 장기간 추적관찰 연구가 많지 않기 때문이라고 생각된다. 2017 년 Keeler 등ํㅡㄴ 클락킹 봉합에 대한 카데바 연구를 시행하 여 휘어진 정도에 따라 비대칭 봉합의 차이(offset)를 어느 정 도 두어야 하는지 연구 결과를 발표하였다. 아직 동양인에서 는 해당 기법을 이용한 배배부 만곡치료에 대한 연구 결과가 발표된 적은 없다. 내측 비밸브의 각도는 예전부터 11 12도 정 도로 알려져 있었으나 2008년 Suh 등 ${ }^{14)}$ 은 동양인의 내측 비밸 브 각도가 19.3도에 이른다고 보고하였다. 따라서 동양인의 경 우 내측 비밸브 비밸브가 좁아져서 문제가 발생하는 경우가 많 지 않으며 비밸브 보강을 위해 펼침 이식 또는 자가 펼침 피판 을 사용해야 할 필요성 또한 낮다고 생각된다. 또한 동양인의 경우 자가 이식물로 사용할 수 있는 연골의 양이 제한적이다. ${ }^{15)}$ 비배부에 추가적인 이식물 삽입 없이 클락킹 봉합을 통해 휜 코를 교정할 경우 남은 연골을 이용하여 비중격 연장이식편 (septal extension graft)이나 비주 지지이식편(columellar strut graft) 등에 사용할 수 있다. 이러한 사실들을 고려할 때 클라 킹 봉합은 오히려 동양인에서 더 적합한 수술 기법으로 판단 되며 앞으로 보다 널리 사용될 수 있을 것으로 판단된다.

본 연구에서 43명 중 42명이 수술결과에 만족하였지만 관 찰자의 평가에서는 43명 중 4명에서 만곡이 덜 교정되었다고 평가되었으며, 이 중 3 명의 경우 만곡이 매우 경미하여 환자가 이에 대한 불만을 제기하지 않았지만 1 명의 경우 눈에 띄는 만곡이 발생하여 재수술을 시행하였다. Fair와 poor로 구분 된 증례의 수술 기록을 분석하였을 때 만곡이 다시 발생한 특 별한 점을 찾을 수 없었다. 다만 재수술을 시행한 증례의 경 우 수술 소견에서 좌측 상외측 비연골이 아래로 처진 소견이 관찰되어 재봉합 후 교정되었으며 이러한 경험으로 미루어 볼 때 클락킹 봉합을 시행할 때 양측 연골 자유연이 충분하게 고
정될 수 있도록 정확하게 봉합과 매듭을 시행하는 것이 중요 하리라 판단된다. 4명 모두에서 만곡은 수술 후 1 3개월 초기 에 발생하였으며, 최대 39개월까지 환자들을 추적 관찰하였 을 때 수술 후 3개월 이후에 만곡이 발생한 지연형 만곡은 발 생하지 않았다. 이러한 사실로 볼 때 본 술식에서 사용된 흡 수성 봉합사인 PDS가 모두 흡수된 후에도 주변 조직의 유 착으로 인해 연골 간 결합은 잘 유지되는 것으로 판단할 수 있다.

\section{REFERENCES}

1) Jang YJ, Wang JH, Lee BJ. Classification of the deviated nose and its treatment. Arch Otolaryngol Head Neck Surg 2008;134(3):311-5.

2) Yoo DB, Jen A. Endonasal placement of spreader grafts: experience in 41 consecutive patients. Arch Facial Plast Surg 2012;14(5):318-22.

3) Rohrich RJ, Gunter JP, Deuber MA, Adams WP Jr. The deviated nose: optimizing results using a simplified classification and algorithmic approach. Plast Reconstr Surg 2002;110(6):1509-23; discussion 1524-5.

4) Moubayed SP, Most SP. The autospreader flap for midvault reconstruction following dorsal hump resection. Facial Plast Surg 2016;32(1):36-41.

5) Kim YH, Yang TY, Lee SJ, Ko BY, Jang TY. Apoptosis of septal cartilage after bilateral spreader grafts in rhinoplasty. J Otolaryngol Head Neck Surg 2011;40(3):244-8.

6) Jang YJ, Kim DY. Treatment strategy for revision rhinoplasty in Asians. Facial Plast Surg 2016;32(6):615-9.

7) Jang YJ, Alfanta EM. Rhinoplasty in the Asian nose. Facial Plast Surg Clin North Am 2014;22(3):357-77.

8) Jang YJ, Yu MS. Rhinoplasty for the Asian nose. Facial Plast Surg 2010;26(2):93-101.

9) Li D, An Y, Yang X. An overview of Asian rhinoplasty. Ann Plast Surg 2016;77 Suppl 1:S22-4.

10) Pontius AT, Leach JL Jr. New techniques for management of the crooked nose. Arch Facial Plast Surg 2004;6(4):263-6.

11) Keeler JA, Moubayed SP, Most SP. Straightening the crooked middle vault with the clocking stitch: an anatomic study. JAMA Facial Plast Surg 2017;19(3):240-1.

12) Song HM, Kim JS, Lee BJ, Jang YJ. Deviated nose cartilaginous dorsum correction using a dorsal L-strut cutting and suture technique. Laryngoscope 2008;118(6):981-6.

13) Jin HR, Lee JY, Shin SO, Choi YS, Lee DW. Key maneuvers for successful correction of a deviated nose in Asians. Am J Rhinol 2006; 20(6):609-14

14) Suh MW, Jin HR, Kim JH. Computed tomography versus nasal endoscopy for the measurement of the internal nasal valve angle in Asians. Acta Otolaryngol 2008;128(6):675-9.

15) Jin HR, Won TB. Rhinoplasty in the Asian patient. Clin Plast Surg 2016;43(1):265-79. 